\title{
Model Design on Emergency Power Supply of Electric Vehicle
}

\author{
Yuanliang Zhao, ${ }^{1}$ Chengpeng $\mathrm{Li}^{2}{ }^{2}$ Mingyu Zhao, ${ }^{3}$ Shiming $\mathrm{Xu}^{3}{ }^{3}$ Hui Gao, ${ }^{4}$ and Le Song ${ }^{4}$ \\ ${ }^{1}$ Guizhou Power Grid Co., Ltd., Guiyang 550000, China \\ ${ }^{2}$ Electric Power Research Institute, Guizhou Power Grid Co., Ltd., Guiyang 550001, China \\ ${ }^{3}$ NARI Technology Development Limited Company, Nanjing 210003, China \\ ${ }^{4}$ Nanjing University of Posts and Telecommunications, Nanjing 210023, China
}

Correspondence should be addressed to Hui Gao; gaohui2005@163.com

Received 22 May 2016; Revised 29 November 2016; Accepted 22 December 2016; Published 9 April 2017

Academic Editor: Haranath Kar

Copyright ( 2017 Yuanliang Zhao et al. This is an open access article distributed under the Creative Commons Attribution License, which permits unrestricted use, distribution, and reproduction in any medium, provided the original work is properly cited.

\begin{abstract}
According to the mobile storage characteristic of electric vehicles, an emergency power supply model about the electric vehicles is presented through analyzing its storage characteristic. The model can ensure important consumer loss minimization during power failure or emergency and can make electric vehicles cost minimization about running, scheduling, and vindicating. In view of the random dispersion feature in one area, an emergency power supply scheme using the electric vehicles is designed based on the $K$-means algorithm. The purpose is to improve the electric vehicles initiative gathering ability and reduce the electric vehicles gathering time. The study can reduce the number of other emergency power supply equipment and improve the urban electricity reliability.
\end{abstract}

\section{Introduction}

Power energy as the modern major energy has irreplaceable function in human daily life [1]. But the stability of the power system is affected by natural disasters and extreme weather. It is significant to prevent accidental large area blackout from happening $[2,3]$.

Urban power grid has its own particularity on the emergency power supply processing. Once the urban power grid crisis happens, the power supply security of hospitals and other important users will be severely affected inevitably [46]. Because the emergency power supply (EPS) equipment is expensive, there is a lack in the configuration quantity in most cities in China. So, to enhance the urban power grid supply emergency capacity, it is particularly important to provide an optimal emergency power allocation scheme [7].

With the increasing size of the electric vehicles in China, they have been applied in EPS as a mobile energy storage device [8-12]. Electric vehicles have many advantages as EPS; for example, users do not need to buy other EPS systems to reduce investment; they ensure uninterrupted power system operation and electric vehicles demand. Besides, as EPS, electric vehicles also can supply power for private houses and public buildings through storing new energy power including wind power and solar power. The application has already been started and the systems V2H (vehicle to home), V2B (vehicle to building), and V2G (vehicle to grid) have been formed and the systems can reduce power outage losses when emergency peak occurs [8]. In addition, electric vehicles are used as battery and can also become critical back-up facilities in optimizing the family electricity home energy management system and realizing intelligent buildings [9]. The advantages and disadvantages and applicable scope of electric vehicles as EPS have been studied in power grids [10]. EV as an urban mobile EPS has been studied [11]. Reference [8] explored the EPS function realization of $V 2 G$ and has given the power mode of EV as EPS. Reference [9] established the EPS optimal matching model based on V2G, with the objective function including the loss in restored power area and the investment costs of V2G as EPS. Reference [12] analyzed the feasibility and the economics of EV as a standby power supply.

In this paper, a regional capacity model of electric vehicles is given by referring to the model in [11], the feasibility of electric vehicles as EPS is analyzed, and a higher precision emergency power supply model is proposed with reference to the optimal matching model in [8]. The emergency power 
supply model contains important user power loss, electric vehicles running, scheduling, and minimum maintenance cost. Based on the emergency power supply model, a kind of EPS scheme is designed for scattered electric vehicles. In the EPS scheme, the $K$-means algorithm is adopted and the electric vehicle users actively participating in the emergency power supply project are assumed. At last, the feasibility and effectiveness of the emergency power supply model as well as the scheme are proven through the electric vehicles and the important load in one city power grid. Compared to the research results in [10] and in [11], the active aggregation function of the electric vehicles in the area is improved, and the mobile storage advantage of city electric vehicles is fully realized. The research results show other EPS equipment number and the loss of user power, and the urban electricity reliability should be improved.

\section{Analysis on EV Capacity}

The most important feature of EPS is power-hold supply for important load if the power blackout occurs. For different users, corresponding size of EPS needs to be configured. Considering the movement storage capacity of EV, the discharge capacity model of the region electric vehicles is given.

$$
\begin{gathered}
W_{\mathrm{EV}}=\sum_{i=1}^{m} W_{\mathrm{EV}-i}=\sum_{i=1}^{m} P_{\mathrm{EV}-i} \cdot t_{p i} \\
W=\sum_{j=1}^{n} W_{j}=\sum_{j=1}^{n} P_{j} \cdot t_{j},
\end{gathered}
$$

where $W_{\mathrm{EV}}$ is the affordable supply of all electric vehicles, $W$ is the important load power, $W_{\mathrm{EV}-i}$ is the affordable supply of $i \mathrm{EV}, W_{j}$ is the electricity of $j$ important user, $P_{\mathrm{EV}-i}$ is the discharge power of $i \mathrm{EV}, P_{j}$ is $j$ actual demand important loads, $m$ is the area electric vehicles sum, $n$ is the area important users sum, $t_{p i}$ is expected power supply time for $i \mathrm{EV}$, and $t_{j}$ is the actual emergency power supply time for $j$ important load.

The capacity model needs to satisfy the constraint conditions as follows:

$$
\begin{aligned}
P_{\mathrm{EV}-i} & \leq P_{\max } \\
P_{i-\max } & =\frac{U_{i} \times I_{i-\max }}{1000} \\
20 \% & \leq \mathrm{SOC}_{i} \leq 100 \%, \\
t_{j} & \leq t_{p i} \\
\sum_{j=1}^{n} P_{j} & \leq \sum_{i=1}^{m} P_{\mathrm{EV}-i} \\
W & \leq W_{\mathrm{EV}}
\end{aligned}
$$

where $P_{i \text {-max }}$ is the single EV maximum discharge power, $U_{i}$ is the $i$ th $\mathrm{EV}$ actual voltage, $I_{i \text {-max }}$ is $i \mathrm{EV}$ maximum discharge current, and $\mathrm{SOC}_{i}$ is $i \mathrm{EV}$ charged state [13].
If the capacity model in (1) meets the constraints in (2) and can achieve discharge at the same time through the scheduling control, the large-scale electric vehicles in the area can be used as a kind of EPS and provide uninterrupted power supply for important users when the urban power grid breaks down.

\section{Model Design of EV as EPS}

The emergency power supply model of electric vehicles is established based on the minimum total consumption cost as the objective function. The optimal matching model in [10] is referred to; the electric capacity configuration and emergency power demand conditions are considered.

3.1. Objective Function. The objective function for emergency power supply is the total consumption costs minimum, including important user power minimal loss, and the EV operation and maintenance costs minimum $[8,10,12,14]$. The important user power loss minimum function is consulted from [8], and the operation and maintenance costs minimum function is referred to in [12]. Its expression is given combined with (1):

$$
\begin{aligned}
& \min f \\
& =\sum_{j=1}^{n} C_{j}\left|\left[\prod_{i=1}^{m}\left(1-Z_{i j}\right)-\prod_{k=1}^{s} Z_{k j}\right] \times I_{j} T_{j}\right| \cdot \eta_{1} \\
& \quad+C_{\mathrm{EV}} \sum_{i=1}^{m} \sum_{j=1}^{n} P_{\mathrm{EV}-i j} Z_{i j}\left[\eta_{2}-\left(1-\eta_{2}\right) \lambda\right] \\
& I_{j}=\frac{P_{j}}{\sum_{j}^{n} P_{j}}\left(A \alpha_{j}+\beta_{j}+\gamma_{j}\right)
\end{aligned}
$$

where $C_{j}$ is $j$ important load loss cost in a unit time and $C_{\mathrm{EV}}$ is the unit capacity cost of EV as EPS. $Z_{i j}$ is the emergency power supply optimal matching decision variable; if $Z_{i j}=1$, that means $i$ EV emergency supplies power for $j$ important load and the value of $Z_{i j}$ is decided by State of Charge (SOC) of the batteries in the battery management system (BMS); if the battery SOC value is greater than $60 \%$ and the $\mathrm{EV}$ is closer to the emergency place, the regional electric vehicle emergency power supply model in Figure 1 will send command to the BMS, and the BMS will remind the EV owner to attend emergency power supply. $Z_{k j}$ is EPS decision variable; if $Z_{k j}=1$, that means $k$ ESP emergency supplies power for $j$ important load and the value of $Z_{k j}$ is decided by the EPS capacity, the location information, and the importance of the outage load; this information is also in the regional electric vehicle emergency power supply model. $s$ is EPS total quantity, $I_{j}$ is the power outage loss comprehensive index of $j$ important load, $T_{j}$ is $j$ important load allowing maximum duration outage, and $P_{\mathrm{EV}-i j}$ is the providing capacity of $i \mathrm{EV}$ for $j$ important load. $\eta_{1}$ is the fatigue coefficient of EV as EPS and is acquired according to 


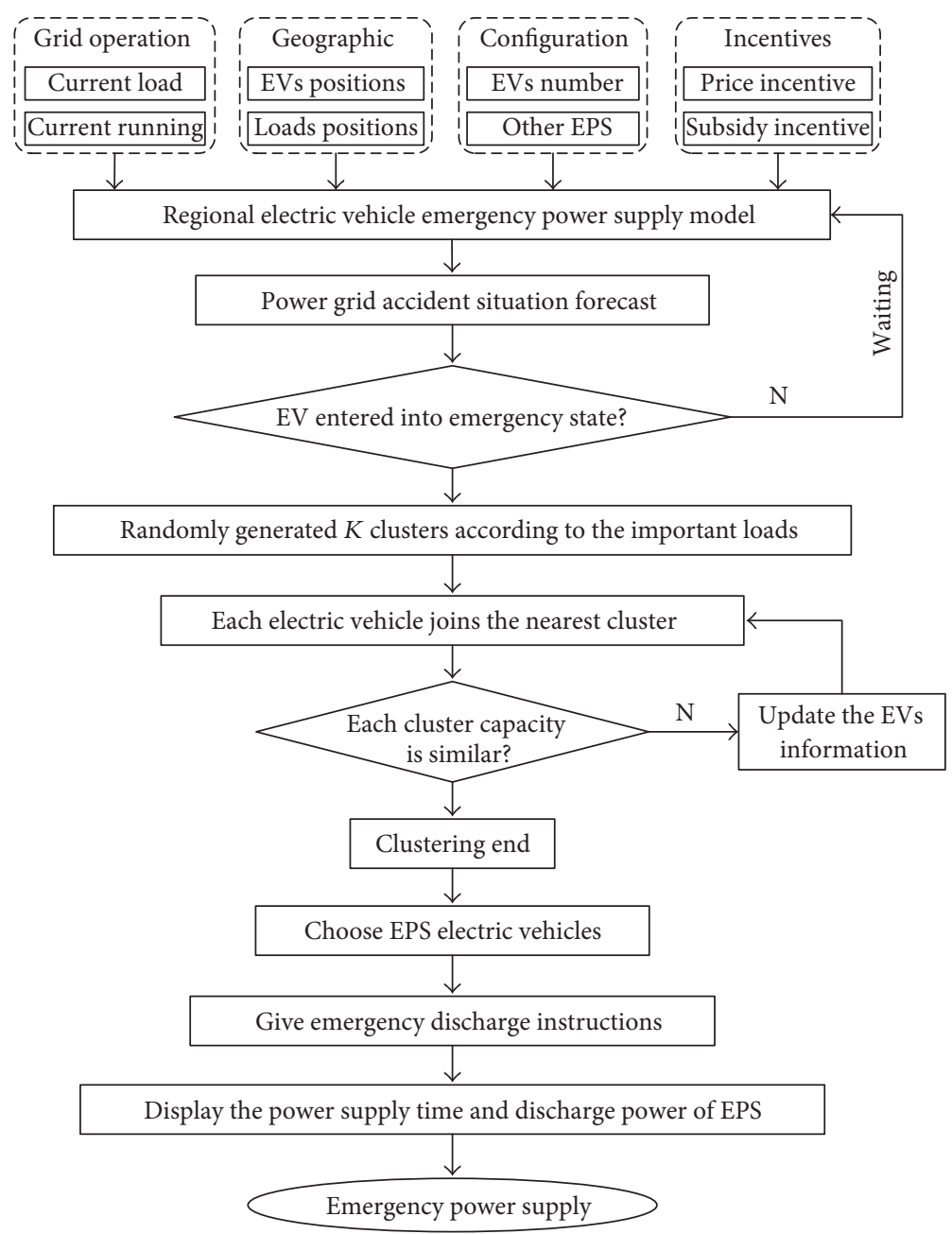

FIGURE 1: The implementation process of EV emergency power supply based on $K$-means algorithm.

empirical estimates, $\eta_{2}$ is the reserved power scaling factor of EV to ensure normal operation, and usually $\eta_{2}$ is decided by the SOC $[8,13] . \lambda$ is the operation, scheduling, and maintenance fee scaling factor of EV as EPS; the value of it is determined from the experience in the operation and maintenance processes of EV [8]. $\alpha_{j}, \beta_{j}$, and $\gamma_{j}$ are life safety, economy, and special weight values, respectively [14]; $A$ is the life safety coefficient, having $A \geq 1$.

\subsection{Constraints}

3.2.1. Time Constraint. The specific time constraint inequality is given combined with (2) and (3) [15]:

$$
t_{i j}+T_{d \max }<T_{j}
$$

where $t_{i j}$ is the maximum time between $i \mathrm{EV}$ and $j$ user and $T_{d \max }$ is the maximum preparing time (time wiring or starting to power supply time) after EV arriving emergency area; this time is decided by the empirical value in daily EV charging work.

\subsubsection{User Demand Capacity Constraint [16]. Consider}

$$
P_{j} \leq \sum_{i=1}^{m_{j}} P_{\mathrm{EV}-i j},
$$

where $m_{j}$ is the number of electric vehicles as EPS for $j$ important load.

\section{Emergency Power Supply Schema Design}

Because of its own particularity, particularly there are many important user loads in the region; the city power grid emergency power supply process should be different with previous large area blackout emergency treatment $[17,18]$. The designed electric vehicle emergency power supply scheme in this paper is based on emergency power supply dispatching platform and can provide emergency power supply work through actively concentrating randomly dispersed electric vehicles in the region. Figure 1 shows the execution process of the electric vehicle emergency power supply scheme.

The emergency power supply dispatching platform in Figure 1 is a tool to ensure that the electric vehicles quickly 
respond emergency power supply for the important loads and collect the city power grid accident information. The information includes the current load of power grid, the positions of scattered electric vehicles and important loads, the numbers of electric vehicles and other EPS, traffic, weather, and incentive subsidy measures information, where the incentive subsidy measures include selling power price incentive of electric vehicles and the number of subsidies and consumption subsidies. The effective electric vehicle emergency power supply scheme is formulated according to the flowchart in Figure 1.

The number of $m$ of the electric vehicles location information vector $(i=1,2, \ldots, m)$ is divided into $K$ fuzzy clusters using fuzzy $K$-means algorithm, and the similarity index of the objective function should be minimum. The objective function can be defined as

$$
\begin{aligned}
& J\left(U, c_{1}, \ldots, c_{K}\right)=\min \sum_{j=1}^{K} J_{j} \cdot I_{j} \\
& =\min \sum_{j=1}^{K} \sum_{i=1}^{m} u_{i j} d_{i j}^{2}\left(x_{i}, c_{j}\right) t_{i j} I_{j} \\
& d_{i j}^{2}\left(x_{i}, c_{j}\right)=\left\|x_{i}-c_{j}\right\| \\
& u_{i j}= \begin{cases}\frac{1}{K}, & j \neq q, \quad \sqrt{\left\|x_{i}-c_{j}\right\|}<\sqrt{\left\|x_{i}-c_{q}\right\|} \\
0, & \text { others, }\end{cases}
\end{aligned}
$$

where $J_{j}$ is the objective function of the fuzzy cluster $j$, $d_{i j}$ is the Euclidean distance from $j$ fuzzy cluster clustering center to $i \mathrm{EV}, c_{j}$ is the clustering center location information, having $j=1, \ldots, K$, the clustering center is consistent with the important load position, $U$ is two-dimensional matrix, having $U=\left\{u_{i j}\right\}_{m \times k}, u_{i j}$ is the similarity index between $i \mathrm{EV}$ and $j$ important load, and $x_{i}$ is the location information of $i$ EV.

The existence necessary condition of (7) is

$$
\begin{aligned}
\sum_{j=1}^{K} u_{i j} & =1, \quad \forall i \\
c_{j} & =\frac{\sum_{j=1}^{K} u_{i j} x_{i}}{\sum_{j=1}^{K} u_{i j}} \\
S_{i} & =d_{i j} \beta S_{u} \\
P_{j} & \leq P_{\mathrm{EV} j} \\
t_{j} & \leq \min \left\{t_{p i}\right\} \\
u_{i j} & =\frac{1}{\sum_{j=1}^{K}\left(d_{i j} / d_{i K}\right)^{2 /(m-1)}},
\end{aligned}
$$

where $S_{i}$ is the subsidy for $i \mathrm{EV}$ consuming electricity when moving, $\beta$ is the relationship coefficient between Euclidean distance and the actual transport distance, $S_{u}$ is the unit distance transportation subsidies, $P_{j}$ is the important load

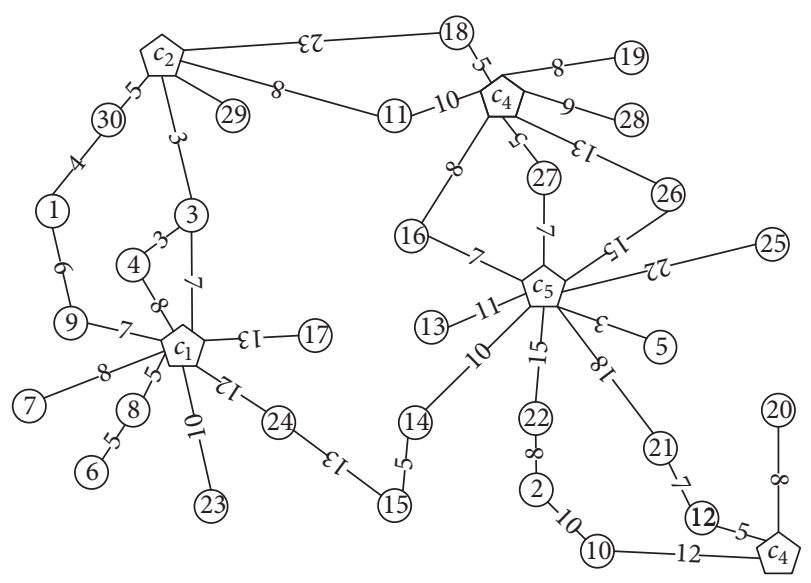

FIgURE 2: Traffic network configuration information.

capacity in cluster $j, P_{\mathrm{EV} j}$ is the total capacity of all electric vehicles in cluster $j$, and $\min \left\{t_{p i}\right\}$ is the $\mathrm{EV}$ minimum power supply time in cluster $j$.

The fuzzy $K$-means algorithm is an iterative learning process by above eight conditions. The clustering center $c_{j}$ and the membership matrix $U$ can be determined through the following steps.

Step 1. The clustering center is initialized, and the membership matrix $U$ is determined by (9) and (10).

Step 2. The clustering centers $c_{j}$ are calculated using (11); here $j \in[1, K]$.

Step 3. The objective function in (7) is counted; if it is less than a certain threshold, the algorithm stops.

Step 4. The user enthusiasm is aroused using (12), and EV's capacity is estimated by (13) and (14). If the judgment meets demand, the cluster ends; otherwise, Step 5 is executed.

Step 5. The $U$ matrix is recalculated using (15); then return to Step 2.

\section{Example Analysis}

Assume that there are 30 electric vehicles in one city power grid. The battery capacity of each EV is $60 \mathrm{Ah}$, the power supply voltage is $400 \mathrm{v}$, and the corresponding electricity is $24 \mathrm{kWh}$. The 30 electric vehicles as EPS offer services to 5 important loads, respectively. The traffic network configuration information is established in Figure 2 through the grid statistical computing and combining with geographical information.

In Figure 2, the number in each branch is the shortest possible time $t_{i j}$ of $\mathrm{EV}$ to the near important load; the unit of $t_{i j}$ is minute. Besides, the expected power supply time $t_{p i}$ is assumed as $75 \mathrm{~min}$ of every electric vehicle. The restore important load properties and index values are shown in Table 1. 
TABLE 1: The restored important load properties values.

\begin{tabular}{lcccccc}
\hline Important load & $P_{j} / \mathrm{kW}$ & $T_{j} / \min$ & $C_{j} /($ thousand yuan $/ \mathrm{h})$ & & $\alpha_{j}$ & $\beta_{j}$ \\
\hline$c_{1}$ & 105 & 20 & 500 & 0.8 & 0.2 \\
$c_{2}$ & 90 & 45 & 300 & 0.3 & 0.6 \\
$c_{3}$ & 70 & 70 & 50 & 0.1 & 0.1 \\
$c_{4}$ & 72 & 56 & 250 & 0.2 & 0.2 \\
$c_{5}$ & 120 & 25 & 420 & 0.6 & 0.6 & 0.3 \\
\hline
\end{tabular}

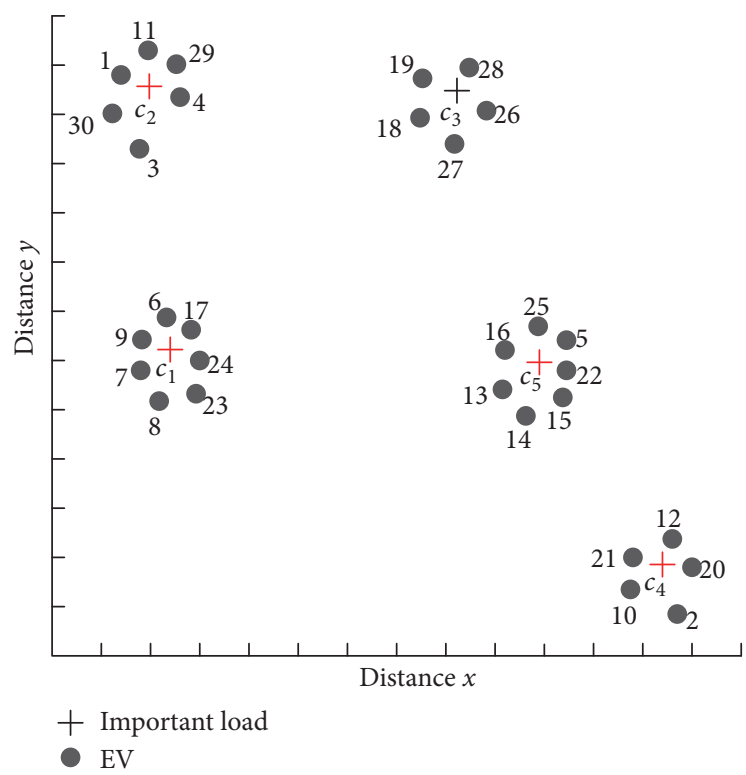

Figure 3: The clustering results of $K$-means algorithm.

TABLE 2: The restored important load outage loss index.

\begin{tabular}{lc}
\hline Important load & Composite index \\
\hline$c_{1}$ & $I_{1}=0.597$ \\
$c_{2}$ & $I_{2}=0.315$ \\
$c_{3}$ & $I_{3}=0.153$ \\
$c_{4}$ & $I_{4}=0.368$ \\
$c_{5}$ & $I_{5}=0.347$ \\
\hline
\end{tabular}

According to the parameters such as capacity and weight coefficient in Table 1, the power outage loss comprehensive index is computed by (4) and shown in Table 2; here, the value of $A$ is 3 .

In Figure 2, the five important loads are assumed as five fuzzy centroids, and the thirty electric vehicles are considered clustering objects. The clustering using $K$-means algorithm is programmed about the five important loads and the thirty electric vehicles; the clustering important information of comprehensive performance index and shortest possible time $t_{i j}$ is given in Table 2 and Figure 2 separately. Figure 3 shows the clustering results using $K$-means algorithm.

After clustering, the capacity constraints in (2), (6), and (13) for the electric vehicles power supply capacity are greater than important load demand capacity. For example, assuming that every EV can provide $75 \%$ of the maximum capacity, it can provide $126 \mathrm{kWh}$ maximum capacities according to the seven electric vehicles clustering results in $c_{5}$; because the demand load power in important load $c_{5}$ is $120 \mathrm{~kW}$, the seven electric vehicles can provide more than an hour continuous power supply time for the important load $c_{5}$. The demand of several other important loads can also be verified according to the clustering results in Figure 3.

The total consumption cost of the emergency power supply model in (3) is calculated; the parameters selection is as follows: $\lambda$ is configured to be $0.68, U_{\mathrm{EV}}$ is 500 yuan, $\eta_{1}$ is 0.8 , $\eta_{2}$ is 0.3 , comprehensive weighting index $I_{j}$ is given in Table 2 , and important load capacity $I_{j}$, maximum outage duration $T_{j}$, and important load loss per unit time $U_{j}$ are shown in Table 1. The minimum total consumption cost is 7.79625 million yuan according to the clustering results in Figure 3 and the model in (3), including the user power outage loss costing 6.36187 million yuan and the electric vehicles operation, scheduling, and maintenance costing 1.34438 million yuan. If electric vehicles do not participate in the emergency power supply, the minimum total cost is about 22.56762 million yuan, including the user power outage loss costing 18.87553 million yuan and other EPS costing 3.69209 million yuan. When using the optimization scheme in [10], the minimum total consumption cost is 9.65396 million yuan, including the user power outage loss costing 7.19863 million yuan and the electric vehicles operation, scheduling, and maintenance costing 2.45633 million yuan.

In view of the above-mentioned results, if the electric vehicles participate in the emergency power supply, the user outage loss cost is decreased to $33.7 \%$ of the original, the minimum total consumption cost is decreased to about $34.5 \%$ of the original, and other EPS investments can also be reduced. Compared with [10], the user power loss reduction is $88.4 \%$.

\section{Conclusion}

In this paper, considering the EV random dispersion characteristics, one kind of actively gathered emergency power supply scheme is proposed based on $K$-means algorithm. The scheme can produce corresponding number of clustering centers according to the important load and the electric vehicles location information, ensure the electric vehicles arrive at the clustering centers in the shortest possible time, and achieve emergency power supply. The study helps to improve the active aggregation capabilities of the electric vehicles in the area, fully tap the electric vehicles movement storage advantages, reduce the investment cost of other EPS 
and the user outage costs, and improve the urban electricity reliability.

\section{Conflicts of Interest}

The authors declare that they have no conflicts of interest regarding the publication of this paper.

\section{Acknowledgments}

This work is supported by the Southern Power Grid Company of Science and Technology Projects of China (GZKJXM20160004) and the National Key Research Projects of China (2016YFB0101800).

\section{References}

[1] N.-C. Yang and M.-D. Le, "Loop frame of reference based harmonic power flow for unbalanced radial distribution systems," International Journal of Electrical Power and Energy Systems, vol. 77, pp. 128-135, 2016.

[2] H. Hou, X. Yin, D. You, Q. Chen, G. Tong, and Y. Zheng, "Apocalypse of overseas experiences on emergency anti-disaster mechanism for China power system," Automation of Electric Power Systems, vol. 32, no. 12, pp. 89-93, 2008.

[3] M. D. Galus, R. A. Waraich, F. Noembrini et al., "Integrating power systems, transport systems and vehicle technology for electric mobility impact assessment and efficient control," IEEE Transactions on Smart Grid, vol. 3, no. 2, pp. 934-949, 2012.

[4] H. Y. Wang, B. H. Zhang, and Z. G. Hao, "Response based emergency control system for power system transient stability," Energies, vol. 8, no. 12, pp. 13508-13520, 2015.

[5] T. Shiming, C. Xi, Z. Chaoyang et al., "Study on electric power emergency management platform," Power System Technology, vol. 32, no. 1, pp. 26-30, 2008.

[6] X. Guo and J. Liu, "Research on power disaster relief resources allocation schedule model," Power System Protection and Control, vol. 39, no. 20, pp. 11-16, 2011.

[7] L. Zhou, M. Fan, and Z. Zhang, "Optimal allocation of emergency power supplies for urban important customers," Dianli Xitong Zidonghua/Automation of Electric Power Systems, vol. 31, no. 6, pp. 99-102, 2007.

[8] L. Zhang, L. Lv, Z. Wei et al., "Optimal assignment of emergency power supply based on EPS functions of V2G," East China Electric Power, vol. 42, no. 1, pp. 122-126, 2014.

[9] L. Lingrong, W. Fushuan, X. Yusheng et al., "Load modeling and parameter identification based on random fuzziness clustering," Automation of Electric Power Systems, vol. 37, no. 14, pp. 43-50, 2013.

[10] Y. Cao, Y. Tan, C. Li, J. Liu, S. Tang, and Z. Zhang, “Typical schemes of electric vehicle charging infrastructure connected to grid," Automation of Electric Power Systems, vol. 35, no. 14, pp. 48-52, 2011.

[11] H. Wang, Z. Lin, F. Wen, Y. Xue, and Y. Li, "Optimal scheduling of urban mobile emergency power sources," Automation of Electric Power Systems, vol. 38, no. 3, pp. 123-129, 2014.

[12] L. Zhou and M. Fan, "Research on customer outage cost assessment and its evaluation method in urban electric power network," Electric Power, vol. 39, no. 7, pp. 70-73, 2006.
[13] S. Zhang, L. Yang, X. Zhao, and J. Qiang, "A GA optimization for lithium-ion battery equalization based on SOC estimation by NN and FLC," International Journal of Electrical Power and Energy Systems, vol. 73, pp. 318-328, 2015.

[14] Z. Aiguo, H. Jiangang, T. Zhifang et al., "The allocation scheme of mobile emergency generator considering the loads importance," Power System Technology, vol. 32, no. 2, pp. 86-89, 2008.

[15] X.-H. Cheng, J.-Y. Liu, H. Feng, X.-Q. He, W.-H. Han, and W.$\mathrm{T}$. $\mathrm{Xu}$, "ADM analysis of power emergency command center to start based on accident state and tendency grade evaluation," Power System Protection and Control, vol. 39, no. 16, pp. 45-52, 2011.

[16] Z. Li, Y. Tian, C. Dong, Y. Fu, and J. Zhang, "Distributed generators programming in distribution network involving vehicle to grid based on probabilistic power flow," Automation of Electric Power Systems, vol. 38, no. 16, pp. 60-66, 2014.

[17] W. Liu, Q. Wu, F. Wen, and Y. Xue, "A market mechanism for participation of electric vehicles and dispatchable loads in distribution system congestion management," Automation of Electric Power Systems, vol. 38, no. 24, pp. 26-33, 2014.

[18] H. Wu, X. Hou, B. Zhao et al., "Management and control scheme for intelligent home appliances based on electricity demand response," Automation of Electric Power Systems, vol. 38, no. 9, pp. 77-85, 2014. 


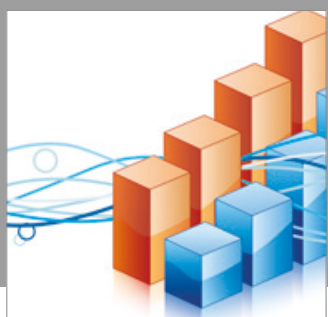

Advances in

Operations Research

vatersals

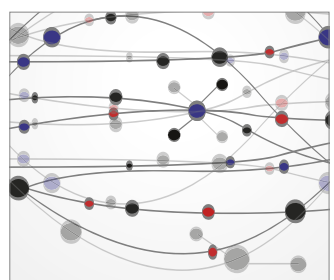

\section{The Scientific} World Journal
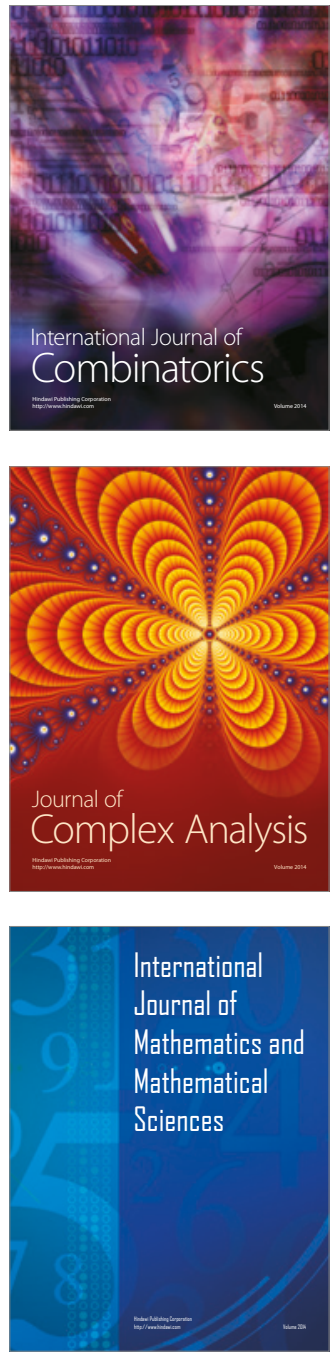
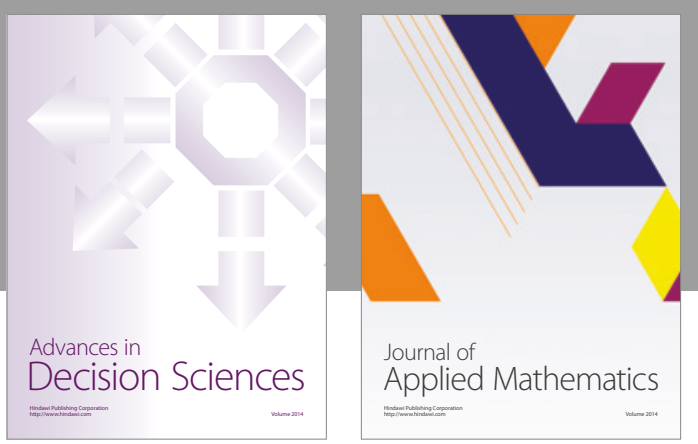

Algebra

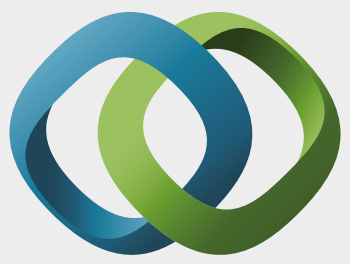

\section{Hindawi}

Submit your manuscripts at

https://www.hindawi.com
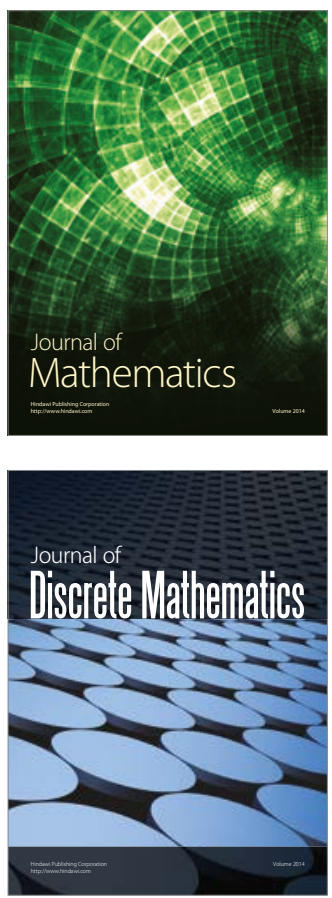

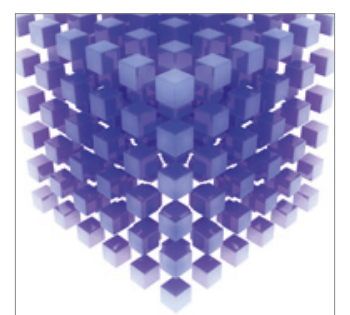

Mathematical Problems in Engineering
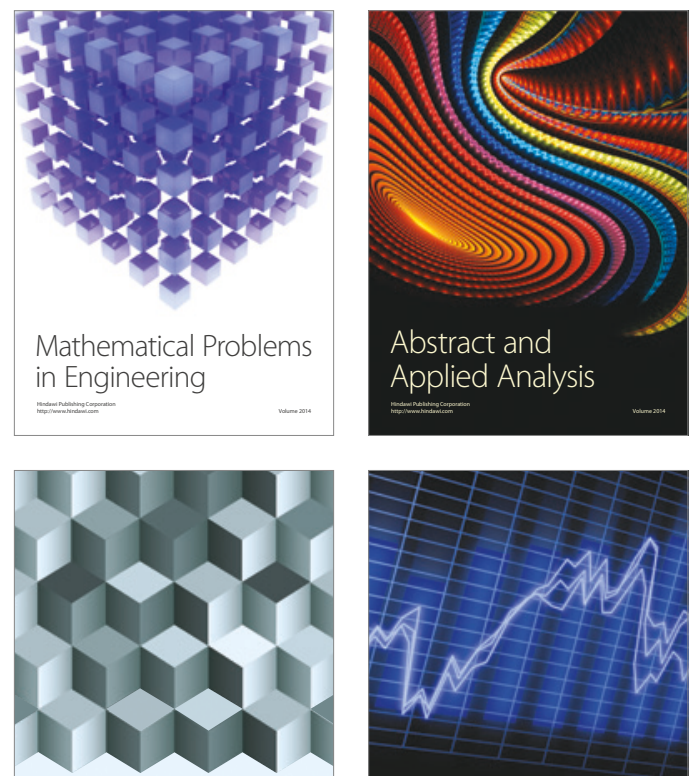

Journal of

Function Spaces

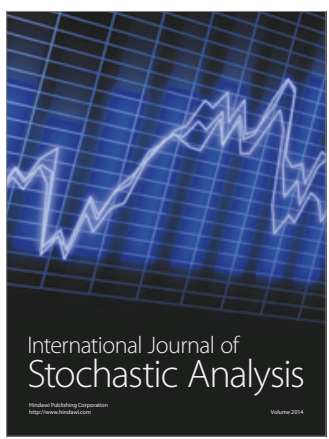

Probability and Statistics
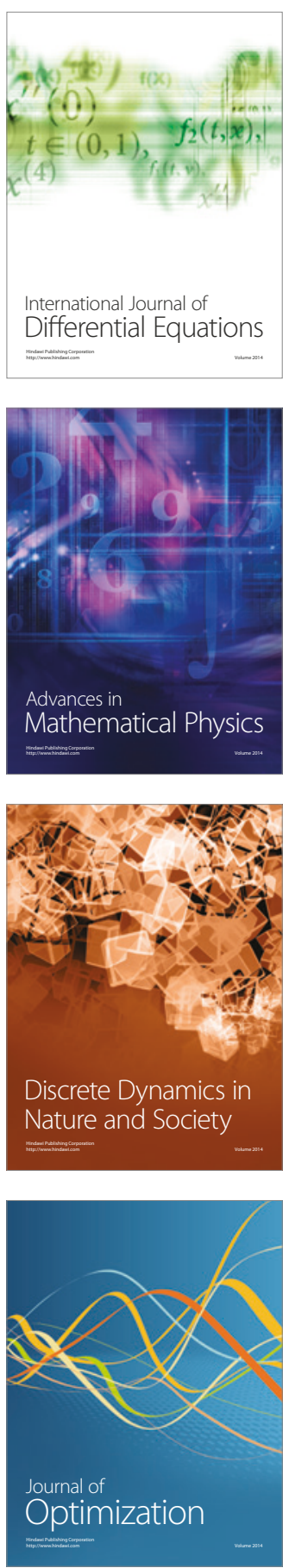